\title{
FENOLOGIA, PRODUÇÃO E TEOR DE ANTOCIANINAS DE CULTIVARES DE MORANGUEIRO EM AMBIENTE PROTEGIDO ${ }^{1}$
}

\author{
EUNICE OLIVEIRACALVETE ${ }^{2}$, FRANCIELE MARIANI ${ }^{3}$, CRISTIANE DE LIMA WESP ${ }^{4}$, \\ ALEXANDRE AUGUSTO NIENOW ${ }^{5}$, TATIANACASTILHOS ${ }^{6}$, DILETACECCHETTI ${ }^{7}$
}

RESUMO - A diversidade de cultivares de morangueiro exige estudos quanto à adaptação no local de cultivo. Por sua vez, a maior exigência do consumidor por produtos mais saudáveis requer informações a respeito das características nutracêuticas dos produtos. Este trabalho objetivou determinar as cultivares com maior adaptação ao cultivo protegido na região do Planalto Médio do Rio Grande do Sul, os teores de antocianinas, bem como a época de plantio que proporcionam maior produtividade. O experimento foi conduzido em um ambiente protegido de $280 \mathrm{~m}^{2}$, coberto com filme de polietileno de baixa densidade (PEBD), de $150 \mu \mathrm{m}$, com aditivo anti UV. O delineamento foi em blocos ao acaso, com três repetições, e os tratamentos em parcelas subdivididas, sendo as épocas de plantio das mudas (28 de abril e 13 de maio) as parcelas principais, e as cultivares (Dover, Tudla, Comander, Oso Grande, Campinas, Chandler, Serrano e Camarosa), as subparcelas. Foram avaliadas características fenológicas e componentes do rendimento. Os teores de antocianinas foram determinados por espectrofotometria, com comprimento de onda de $528 \mathrm{~nm}$. Não houve interação entre cultivares e épocas de plantio sobre as características avaliadas. A maior produtividade foi do morangueiro cultivado precocemente, em abril. As cultivares Camarosa, Dover, Oso Grande e Tudla são as mais indicadas, pelo maior rendimento e escalonamento da produção, e a cultivar Serrano, pelo maior teor de antocianinas.

Termos para indexação: Fragaria x ananassa Duch., época de plantio, valor nutracêutico.

\section{PHENOLOGY, PRODUCTION AND CONTENT OF STRAWBERRY CROPS CULTIVARS ANTHOCYANINS PRODUCED UNDER PROTECTED ENVIRONMENT}

\begin{abstract}
The diversification of strawberry cultivars demands studies about their adaptation in the cultivation place and, the increase of the consumer's requirement for healthier products require studies about the products nutraceutica characteristics. In such a way, this work aimed to determine the cultivars with higher adaptation under protected environment in Rio Grande do Sul, Planalto Médio region, the contents of anthocyanins, as well as the period that provides more productivity. The experiment was conduced in an inside structure of $280 \mathrm{~m}^{2}$ covered with PEBD film, with $150 \mu \mathrm{m}$ and anti UV additive. The designs were arranged in split plots with 3 repetitions, the treatments in subdivided portions, and the period for planting seedlings (April $28^{\text {th }}$ and May $13^{\text {th }}$ ) the main plots, and the cultivars (Dover, Tudla, Comander, Oso Grande, Campinas, Chandler, Serrano e Camarosa), the sub-plots. Phenological characteristics and yield components were evaluated. The content of anthocyanins was determinated by using a specterphotometer with wave length of $528 \mathrm{~nm}$. There was no interaction between cultivars and planting periods about the evaluated characteristics. The higher productivity was the earlier planting strawberry crop in April. The cultivars Camarosa, Dover, Oso Grande and Tudla are the most recommended for their greater productivities and range of production periods, and "Serrano" cultivar for higher antocianin levels. Index terms: Fragaria $\mathrm{x}$ ananassa Duch., plantation period, nutraceutic value.
\end{abstract}

\section{INTRODUÇÃO}

O morangueiro atualmente cultivado (Fragaria $\mathrm{x}$ ananassa Duch., Rosaceae), originou-se do cruzamento entre Fragaria chiloensis e F. virginiana, ocorrido espontaneamente na França, por volta de 1750 (Santos, 1999). É uma planta herbácea, rasteira e, embora tenha características de cultura perene, é cultivada como anual.
A produção brasileira de morangos é de cerca de $90.000 \mathrm{t}$ ano $^{-1}$, colocando o Brasil em posição de destaque entre os principais produtores mundiais, embora distante dos Estados Unidos, com mais de 700.000 t (Assis, 2004). A produção concentra-se nos Estados de Minas Gerais $(41,4 \%)$, Rio Grande do Sul (25,6\%), São Paulo (15,4\%), Paraná (4,7\%) e Distrito Federal (4\%). O cultivo destina-se a atender ao mercado in natura e à industrialização na forma de geléias, sucos e polpa, para adição em outros alimentos (Pagot \& Hoffmann, 2003).

'(Trabalho159-07). Recebido em: 21-06-2007. Aceito para publicação em : 19-12-2007. Projeto financiado pela Secretaria de Ciência e Tecnologia do Rio Grande do Sul.

${ }^{2}$ Enga.-Agra., Dra., profa. de Olericultura da Faculdade de Agronomia e Medicina Veterinária (FAMV) da Universidade de Passo Fundo (UPF), Campus I, Passo Fundo, RS, Cx. Postal 611, CEP 99001-970, calveteu@upf.br.

${ }^{3}$ Acadêmica de Agronomia da FAMV/UPF e Bolsista Probic II/FAPERGS. francielemariani@bol.com.br.

${ }^{4}$ Acadêmica de Agronomia da FAMV/UPF e Bolsista FAPERGS. cristianewesp@yahoo.com.br.

${ }_{5}^{5}$ Eng.-Agr., Dr., prof. de Fruticultura da FAMV/UPF, Campus I, Passo Fundo, RS, Cx. Postal 611, CEP 99001-970, alexandre@upf.br.

${ }^{6}$ Farmacêutica, Ms., profa. de Farmacognosia I e II da UPF. tcastilhos@bol.com.br.

${ }^{7}$ Matemática, Ms., profa. de Estatística da UPF. cecchetti@upf.br.

Rev. Bras. Frutic., Jaboticabal - SP, v. 30, n. 2, p. 396-401, Junho 2008 
As principais cultivares de morangueiro no Brasil provêm dos Estados Unidos (Aromas, Camarosa, Dover, Oso Grande e Sweet Charlie), da Espanha (Milsei-Tudla) e dos programas de melhoramento genético da Embrapa Clima Temperado (Bürkley, Santa Clara e Vila Nova) e do Instituto Agronômico de Campinas - IAC (Campinas) (Brahm et al., 2005).

Verdial (2004) relata que a maioria das cultivares de morangueiro plantadas no Brasil são de fotoperíodo de dias curtos, ou seja, florescem quando o comprimento do dia se torna menor que 14 horas, e as temperaturas inferiores a $15^{\circ} \mathrm{C} . \mathrm{Em}$ épocas com condições diferentes ocorre a emissão dos estolhos. Entretanto, existem cultivares que florescem continuamente, independentemente do fotoperíodo, sendo denominadas cultivares neutras. Nestes casos, a floração cessa com temperaturas iguais ou abaixo de $10^{\circ} \mathrm{C}$, ou acima de $28^{\circ} \mathrm{C}$ (Santos, 1999).

A utilização do ambiente protegido na cultura do morangueiro proporciona uma série de vantagens, destacandose a proteção da cultura contra ventos, granizo, chuvas, geadas, baixas temperaturas e do ataque de pragas e doenças. Em ambiente protegido, Schwengber et al. (1996), em Pelotas-RS, constataram evidente superioridade no rendimento e qualidade dos frutos das cvs. Chandler e Sequóia, comparadas com o cultivo a campo. Calvete et al. (2003), testando nove cultivares em ambiente protegido, na Região de Passo Fundo-RS, verificaram melhor adaptação das cvs. Tudla e Oso Grande, com produtividade de $44 \mathrm{t} \mathrm{ha}^{-1}$ e $31 \mathrm{t} \mathrm{ha}^{-1}$, respectivamente, apresentando também frutos de melhor qualidade.

Duarte Filho et al. (2004), em MG, observaram que o cultivo protegido favoreceu a precocidade de diferentes cultivares (Campinas, Cigaline, Cireine, Cidaly e Cigoulette). De maneira geral, o ambiente protegido proporcionou melhores condições ao desenvolvimento da planta e aumento da frutificação e da produção comercial, conferindo maior proteção aos frutos e diminuindo a ocorrência de frutos danificados.

Nos últimos anos, a atração dos consumidores pelas denominadas "pequenas frutas" (morango, amora-preta, framboesa, mirtilo e fisalis, entre outras) tem sido elevada, pelo valor nutracêutico. Os produtores rurais, por sua vez, em virtude do alto valor do produto no mercado, têm ampliado gradativamente as áreas de cultivo.

Conforme Liu (2006), o Cranberry (fruta da mesma espécie do mirtilo), a maçã, a uva tinta e o morango são as principais espécies em conteúdo de flavonóides, que possuem variada estrutura química, sendo divididos em subgrupos, como as flavonas e flavonóis, os flavonóides C-heterosídeos, as flavanas e os isoflavonóides, entre outros (Simões et al., 2003). Os compostos fenólicos são um grupo com atividade antioxidante, identificado em frutas, hortaliças, cereais e leguminosas, ligado à redução da maioria das doenças crônicas de risco, principalmente as degenerativas (Henriques et al., 2004), combatendo os radicais livres. As antocianinas são flavonóides solúveis em água, derivados dos hidroflavonóis, sendo um dos mais importantes grupos de pigmentos das plantas, juntamente com as betaínas e os carotenóides, responsáveis pelas colorações das pétalas, flores e frutos (Simões et al., 2003) No entanto, na maioria das vezes, os teores dessas substâncias, em cultivares utilizadas nas diferentes regiões de produção, não são conhecidos.

Com base neste contexto, este trabalho objetivou determinar a fenologia, o potencial produtivo e o teor de antocianinas de oito cultivares de morangueiro plantadas em duas diferentes épocas, em ambiente protegido.

\section{MATERIAL E MÉTODOS}

O trabalho foi conduzido em ambiente protegido, localizado no Câmpus da Universidade de Passo Fundo, Rio Grande do Sul, situada na latitude de $28^{\circ} 15^{\prime} 41^{\prime}$ ' S, longitude de $52^{\circ} 24^{\prime} 45^{\prime \prime}$ O e altitude de $709 \mathrm{~m}$. A estrutura é de madeira, instalada no sentido nordeste-sudoeste, com $280 \mathrm{~m}^{2}$, teto semicircular, coberta com filme de polietileno de baixa densidade (PEBD), com aditivo antiultravioleta e espessura de $150 \mathrm{~mm}$.

Foram estudadas, em duas épocas de plantio ( $28 \mathrm{de}$ abril e 13 de maio de 2005), oito cultivares de morangueiro (Comander, Camarosa, Campinas, Tudla, Chandler, Oso Grande, Dover e Serrano). O delineamento experimental foi em blocos ao acaso, com três repetições, com os tratamentos arranjados em parcelas subdivididas, constituindo as parcelas principais as épocas de plantio e as cultivares, as subparcelas. Cada parcela constou de 12 plantas, com seis plantas úteis, dispostas no espaçamento de $0,3 \mathrm{~m} \times 0,5 \mathrm{~m}$, compreendendo $1,8 \mathrm{~m}^{2}$ de canteiro.

Após o estabelecimento das mudas, foi colocado mulching preto. A irrigação foi por gotejamento, com mangueiras fixas e gotejadores a cada $0,3 \mathrm{~m}$. Os tratamentos fitossanitários foram realizados quando necessário, para o contole de oídio e ácaro rajado.

No ambiente interno, do ambiente protegido,foram monitoradas a temperatura e a umidade relativa do ar (Figura 1), utilizando um termoigrógrafo de registro semanal. Os valores médios diários foram obtidos pelas seguintes expressões: $\mathrm{T}_{\text {média }}$ $=\left[\mathrm{T}(9)+2 \times \mathrm{T}(21)+\mathrm{T}_{\text {máx }}+\mathrm{Tmín}\right] / 5 \mathrm{e} \mathrm{UR}_{\text {média }}=[\mathrm{UR}(9)+\mathrm{UR}(15)$ $+2 \times \operatorname{UR}(21)] / 4$ (Nienow, 1997).

Quanto à fenologia, avaliaram-se o início da floração e o início e final da colheita, em dias transcorridos após o plantio. Com relação aos componentes do rendimento, foram avaliados: número e massa fresca de frutos por planta $\left(\mathrm{g} \mathrm{planta}^{-1}\right)$; número, massa fresca $\left(\mathrm{g} \mathrm{planta}^{-1}\right)$ e porcentagem de frutos comerciais por planta (\%). Foram considerados frutos comerciais aqueles com mais de $6 \mathrm{~g}$, desprovidos de injúrias, doenças e deformações.

$\mathrm{O}$ teor de antocianinas foi determinado por espectrofotometria, com comprimento de ondas de $528 \mathrm{~nm}$, representado em porcentagem (\%) de cianidina-3-glicosídeo (Henriques et al., 2004). A extração foi feita com etanol 95\%, sob agitação, a partir de três amostras com massa de $15 \mathrm{~g}$ (cerca de dois frutos), retiradas aleatoriamente no experimento.

Os dados de fenologia foram comparados pela média mais ou menos um desvio-padrão. Os resultados de rendimento e teores de antocianinas foram submetidos à análise de variância, e as diferenças entre médias, comparadas pelo teste de Tukey, a $5 \%$ de significância. 


\section{RESULTADOS E DISCUSSÃO}

O conhecimento da fenologia das cultivares é importante para definir o escalonamento da produção e, com isso, ampliar o período de safra, possibilitando vantagens na comercialização. O início da floração variou entre as cultivares, de 38 a 54 dias, após o plantio em 28 de abril (época 1), e de 41 a 48 dias, com o plantio em 13 de maio (época 2) (Tabela 1), sendo a cv. Dover a mais precoce. Em relação ao início da colheita, as cvs. Dover e Comander foram as mais precoces, quando plantadas na época 1. A precocidade da 'Dover' é confirmada por outros autores, como Bueno et al. (2002) e Antunes et al. (2006). O início da colheita foi mais tardio nas cvs. Campinas e Chandler, quando plantadas mais precocemente. Na época 2 de plantio, novamente a cv. Campinas, e também Oso Grande, iniciaram a colheita mais tarde. A determinação de encerrar a colheita em 27 de dezembro foi devido ao incremento na emissão de estolões, induzido pelo aumento da temperatura (Figura 1), e conseqüente redução acentuada da formação de flores e frutos. Apenas a cv. Campinas de fato finalizou o ciclo produtivo mais cedo ( 25 de dezembro), não apresentando frutos a serem colhidos.

Não houve efeito significativo da interação épocas de plantio $\mathrm{x}$ cultivares, mas, sim, dos fatores isoladamente, para as características estudadas (Tabela 2). Na comparação entre épocas de plantio, os resultados obtidos mostram que, quando plantado mais precocemente, houve incremento no número e massa fresca total e de frutos comerciais de morangueiro por planta. Esses dados indicam a possibilidade de antecipar a época de plantio para a região do Planalto Médio do RS, estendendo o ciclo produtivo e o rendimento.

A cv. Dover apresentou o maior número de frutos por planta (Tabela 2), não diferindo de Camarosa, Chandler e Oso Grande. Considerando apenas os frutos com padrão comercial, destacaram-se, principalmente, as cvs. Camarosa, Dover e Oso Grande. As cvs. Comander e Campinas produziram o menor número de frutos total e comerciais por planta, refletindo, especialmente, a cv. Campinas, na massa de frutos por planta. Em relação ao total de frutos produzidos, as cvs. Oso Grande e Tudla destacaram-se pela maior porcentagem de frutos comerciais, não diferindo estatisticamente de Comander, Serrano e Camarosa. A cv. Tudla, embora não tenha se destacado pela produção em número e massa de frutos por planta, apresentou frutos de elevada massa média $(11,3 \mathrm{~g})$, com excelente valor comercial.

Castro et al. (2003), trabalhando em Viçosa-MG, no sistema de cultivo orgânico a campo, também obtiveram maior número de frutos na cv. Dover (54,9 frutos planta ${ }^{-1}$ ), comparado com as cvs. Campinas e Princesa Isabel, mas inferior ao proporcionado por essa mesma cultivar no presente trabalho. Pallamin et al. (2003), testando nove cultivares em Bauru- SP, também observaram superioridade das cvs. Oso Grande e Tudla para número de frutos.

Apesar do maior número de frutos produzidos pela cv. Dover (Tabela 2), a porcentagem de frutos comerciais foi baixa (55\%), não diferindo da 'Campinas' (44\%). Duarte Filho et al. (2003) observaram que o problema da 'Dover' é a grande produção de frutos com tamanho e massa abaixo do padrão comercial, devido às características de suas inflorescências, que possuem muitas ramificações. Porém, a grande vantagem é a maior precocidade, em relação às demais cultivares.

A maior massa fresca total e comercial de frutos foi proporcionada pela cv. Camarosa, seguida das cvs. Dover e Oso Grande (Tabela 2). O bom desempenho da cv. Camarosa é confirmado pelos resultados de Duarte Filho et al. (2003), que relatam que a mesma vem sendo cultivada na maioria dos países produtores de morango, pois possui boa adaptação. Também Oliveira \& Scivittaro (2006), em Pelotas-RS, observaram produção de $570 \mathrm{~g} \mathrm{planta}^{-1}$, evidenciando a sua potencialidade e perspectivas de obtenção de ganhos consideráveis por parte de produtores de morango.

$\mathrm{O}$ teor de antocianina poderá apresentar-se como um critério de escolha de cultivares, além da produtividade, em razão dos benefícios à saúde. As cvs. Serrano e Comander destacaramse pelas maiores concentrações, enquanto os frutos da 'Chandler' possuem o teor mais baixo, não diferindo de Campinas. Henriques et al. (2004) constataram variações nos teores de antocianinas em uvas e mirtilo. Da mesma forma, Maro et al. (2004), em MG, observaram diferenças ao comparar os teores fenólicos totais dos frutos de morango das cvs. Guarani, Dover e Sweet Charlie. A cv. Guarani apresentou o maior teor de antocianina $(19,5 \mathrm{mg}$ $\left.100 \mathrm{~g}^{-1}\right)$, enquanto Dover (14,3 mg $\left.100 \mathrm{~g}^{-1}\right)$ e Sweet Charlie (13,3 $\left.\mathrm{mg} 100 \mathrm{~g}^{-1}\right)$, os menores teores, concentrações estas inferiores às obtidas no presente experimento.

Além da variação do teor de antocianinas entre cultivares, o sistema de cultivo também pode influenciar. Por exemplo, em outro trabalho conduzido em Passo Fundo, morangos da cv. Oso Grande produzidos em ambiente protegido apresentavam maior concentração de flavonóides $(30 \mathrm{mg} 100 \mathrm{~g}$ $\left.{ }^{1}\right)$ em relação aos do campo (11 mg $\left.100 \mathrm{~g}^{-1}\right)$. Em Minas Gerais, Guimarães et al. (2006) verificaram o teor de antocianinas e flavonóis em morangos cultivados em sistema orgânico. A 'Dover' apresentou a maior concentração de antocianinas, seguida por 'Sweet Charlie', e 'Aleluia' os menores teores. Também em Minas Gerais, em produção de morangos sem agrotóxicos, Souza et al. (2006) encontraram maiores teores de antocianina e flavonóis na 'Dover', utilizando serragem como cobertura da superfície dos canteiros e irrigação por microaspersão, ou sobre NãoTecido ${ }^{\circledR}$ Agrícola, com irrigação por gotejamento. Dessa forma, os relatos comprovam que ocorrem diferenças entre os ambientes e as cultivares utilizadas, bem como o sistema de cultivo, influenciando no teor de antocianos e flavonóides em frutas e hortaliças. 


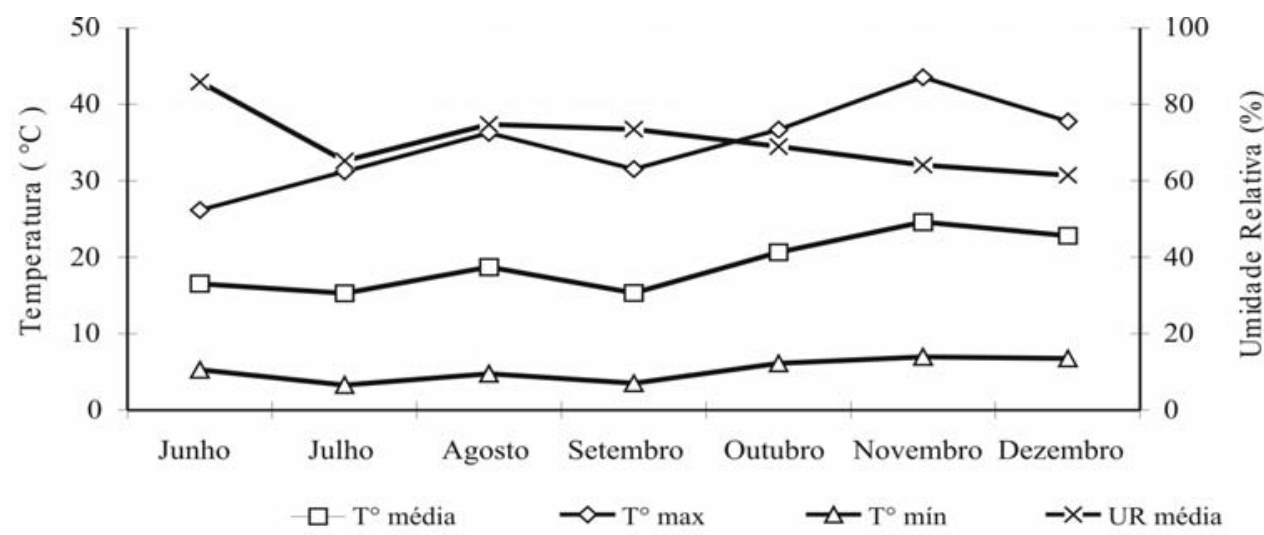

FIGURA 1 - Média das temperaturas médias, máximas e mínimas, e da umidade relativa do ar no interior do ambiente protegido, no período de junho a dezembro de 2005. Passo Fundo-RS, FAMV/UPF.

TABELA 1 - Dias transcorridos desde o plantio, em duas épocas, ao início da floração e início/final da colheita, de oito cultivares de morangueiro, em ambiente protegido. Passo Fundo-RS, FAMV/UPF, 2005

\begin{tabular}{|c|c|c|c|c|c|c|}
\hline \multirow{3}{*}{ Cultivares } & \multicolumn{2}{|c|}{ Início da floração } & \multicolumn{2}{|c|}{$\begin{array}{l}\text { Início da colheita } \\
\text { (dias após o plantio) }\end{array}$} & \multicolumn{2}{|c|}{ Final da colheita } \\
\hline & \multicolumn{6}{|c|}{ Datas de plantio } \\
\hline & 28/abril & 13/maio & 28/abril & $13 /$ maio & 28/abril & 13/maio \\
\hline Dover & $38(-)$ & $41(-)$ & $61(-)$ & 62 & 237 & 222 \\
\hline Camarosa & 41 & 44 & 67 & 62 & 237 & 222 \\
\hline Comander & 47 & 46 & $61(-)$ & 68 & 237 & 222 \\
\hline Oso Grande & 46 & $48(+)$ & 67 & $77(+)$ & 237 & 222 \\
\hline Campinas & 49 & 47 & $78(+)$ & $81(+)$ & $222(-)$ & $207(-)$ \\
\hline Serrano & 42 & 46 & 67 & 68 & 237 & 222 \\
\hline Chandler & $52(+)$ & $48(+)$ & $78(+)$ & 62 & 237 & 222 \\
\hline Tudla & $54(+)$ & 45 & 67 & 62 & 237 & 222 \\
\hline Média \pm desvio-padrão & $46,1 \pm 5,5$ & $45,6 \pm 2,3$ & $68,3 \pm 6,6$ & $67,8 \pm 7,5$ & $235,1 \pm 5,3$ & $220,1 \pm 5,3$ \\
\hline
\end{tabular}

$(-)$ precoces (+) tardias

TABELA 2 - Número e massa fresca total e de frutos comerciais por planta, porcentagem de frutos comerciais e teor de antocianinas de oito cultivares de morangueiro, em duas épocas de plantio, em ambiente protegido. Passo Fundo-RS, FAMV/UPF, 2005 .

\begin{tabular}{|c|c|c|c|c|c|c|}
\hline Épocas de plantio & $\begin{array}{l}N^{\circ} \text { total de } \\
\text { frutos por } \\
\text { planta }\end{array}$ & $\begin{array}{c}* N^{\circ} \text { de } \\
\text { frutos } \\
\text { comerciais } \\
\text { por planta }\end{array}$ & $\begin{array}{c}* \text { Frutos } \\
\text { comerciais } \\
(\%)\end{array}$ & $\begin{array}{c}\text { Massa fresca } \\
\text { total de frutos } \\
\left(\mathrm{g} \text { planta }^{-1}\right)\end{array}$ & $\begin{array}{l}\text { Massa fresca } \\
\text { de frutos } \\
\text { comerciais } \\
\left(\mathrm{g} \text { planta }{ }^{-1}\right) \\
\end{array}$ & $\begin{array}{c}\text { Teor de } \\
\text { antocianinas } \\
\left(\mathrm{mg}^{\left.100 g^{-1}\right)}\right.\end{array}$ \\
\hline Época 1 (28-04) & $60,0 \mathrm{a}$ & $39,4 \mathrm{a}$ & 65,7 a & $530 \mathrm{a}$ & $439 \mathrm{a}$ & - \\
\hline Época 2 (13-05) & $47,5 \mathrm{~b}$ & $29,0 \mathrm{~b}$ & $61,1 \mathrm{a}$ & $366 \mathrm{~b}$ & $297 \mathrm{~b}$ & - \\
\hline \multicolumn{7}{|l|}{ Cultivares } \\
\hline Camarosa & $69,6 \mathrm{ab}$ & $46,4 \mathrm{a}$ & $66,0 \mathrm{abc}$ & $607 \mathrm{a}$ & 517 a & $40 \mathrm{~b}$ \\
\hline Dover & $78,0 \mathrm{a}$ & $43,5 \mathrm{a}$ & $55,0 \mathrm{~cd}$ & $549 \mathrm{ab}$ & $423 \mathrm{ab}$ & $38 \mathrm{~b}$ \\
\hline Oso Grande & $53,4 \mathrm{abc}$ & $41,5 \mathrm{ab}$ & $78,0 \mathrm{a}$ & $536 \mathrm{ab}$ & $415 \mathrm{ab}$ & $30 \mathrm{bc}$ \\
\hline Tudla & $47,7 \mathrm{bc}$ & $34,3 \mathrm{abc}$ & $71,0 \mathrm{a}$ & 443 abc & 388 abc & $39 \mathrm{~b}$ \\
\hline Chandler & $59,1 \mathrm{abc}$ & $34,0 \mathrm{abc}$ & $58,0 \mathrm{bc}$ & $432 \mathrm{abc}$ & $338 \mathrm{abc}$ & $21 \mathrm{~cd}$ \\
\hline Serrano & $47,9 \mathrm{bc}$ & $32,8 \mathrm{abc}$ & $69,0 \mathrm{ab}$ & $421 \mathrm{abc}$ & $363 \mathrm{abc}$ & $56 \mathrm{a}$ \\
\hline Comander & $33,7 \mathrm{c}$ & $23,8 \mathrm{bc}$ & $69,0 \mathrm{ab}$ & $323 \mathrm{bc}$ & $284 \mathrm{bc}$ & 54 a \\
\hline Campinas & $41,1 \mathrm{c}$ & $18,1 \mathrm{c}$ & $44,3 \mathrm{~d}$ & $232 \mathrm{c}$ & $158 \mathrm{c}$ & $25 \mathrm{c}$ \\
\hline C.V. a $(\%)$ & 22,89 & 17,80 & 4,49 & 20,45 & 19,25 & - \\
\hline C.V. b (\%) & 24,97 & 27,69 & 10,35 & 30,38 & 32,98 & 12,22 \\
\hline
\end{tabular}

Médias seguidas da mesma letra nas colunas não diferem entre si, pelo teste de Tukey, a 5\% de significância.

* Frutos com massa superior a $6 \mathrm{~g}$, desprovidos de injúria, doenças e deformados. 


\section{CONCLUSÕES}

1-No Planalto Médio do Rio Grande do Sul, em ambiente protegido, recomenda-se o plantio mais precoce do morangueiro, em final de abril, para obtenção de maior produtividade.

2-As cultivares Camarosa, Dover, Oso Grande e Tudla são as mais indicadas pelo maior rendimento e escalonamento da produção.

3-Para produtores que buscam especializar-se em produzir cultivares com maior teor de antocianinas, a cv. Serrano é a mais indicada.

\section{REFERÊNCIAS}

ANTUNES, T.O.; CALVETE, E.O.; ROCHA, H.C.; NIENOW, A.A.; MARIANI, F.; WESP, C.L. Floração, frutificação e maturação de frutos de morangueiro cultivados em ambiente protegido. Horticultura Brasileira, Brasília, v.24, n.4, p.426-430, 2006.

ASSIS, M. de. Produção de matrizes e mudas de morangueiro no Brasil. In: SIMPÓSIO NACIONAL DO MORANGO, 2., ENCONTRO DE PEQUENAS FRUTAS E FRUTAS NATIVAS, 1., 2004, Pelotas. Anais... Pelotas: Embrapa Clima Temperado, 2004. p.45-50. (Documentos, 124).

BRAHM, R.U.; UENO, B.; OLIVEIRA, R.P. Reação de cultivares de morangueiro ao oídio sob condições de casa de vegetação. Revista Brasileira de Fruticultura, Jaboticabal, v.27, n.2, p.219$221,2005$.

BUENO, S.C.S.; MAIA, A.H.N.; TESSARIOLI NETO, J. Florescimento de 17 cultivares de morangueiro (Fragaria $\mathrm{x}$ ananassa Duch.), em São Bento do Sapucaí - São Paulo.In: CONGRESSO BRASILEIRO DE FRUTICULTURA, 17., Belém. Anais... Belém: SBF, 2002. CD-ROM.

CALVETE, E.O.; CECCHETTI, D.; BORDIGNON, L. Desempenho de cultivares de morangueiro em ambiente protegido. Horticultura Brasileira, Brasília, v.21, n.2, 2003. Suplemento CDROM.

CASTRO, R.L.; CASALI, V.W.D.; BARRELLA, T.P.; SANTOS, R.H.S.; CRUZ, C.D. Comportamento de dez cultivares de morangueiro em cultivo orgânico. Horticultura Brasileira, Brasília, v.21, n.2, p.227-230, 2003.

DUARTE FILHO, J.; ANTUNES, L.E.C.; PÁDUA, J.G. GA 3 e Paclobutrazol no florescimento e na produção de frutos em duas cultivares de morangueiro. Horticultura Brasileira, Brasília, v.22, n.2, p.202-205, 2004.

DUARTE FILHO, J.; ANTUNES, L.E.C.; PÁDUA, J.G. Introdução e avaliação de cultivares de morangueiro no Sul de Minas Gerais.
Horticultura Brasileira, Brasília, v.21, n.2, 2003. Suplemento. CD-ROM.

GUIMARÃES, F.N.; DIAS, M.S.C.; FERNANDES, M.B.; CARVALHO, L.M.; MARO, L.A.C.; LANZA, F.E. Teor de antocianinas e flavonóis em morangos cultivados no sistema orgânico na região norte de Minas Gerais. Produção do ano de 2005. In: CONGRESSO BRASILEIRO DE FRUTICULTURA, 19. 2006, Cabo Frio. Palestras e resumos... Rio de Janeiro: SBF/ UENF/UFRuralRJ, 2006. p.448.

HENRIQUES, A.T.; BASSANI, V.L.; RASEIRA, M. do C.; ZUANAZZI, J.A. Antocianos e capacidade antioxidante de frutas. In: SIMPÓSIO NACIONAL DO MORANGO, 2., ENCONTRO DE PEQUENAS FRUTAS E FRUTAS NATIVAS, 1 ., 2004, Pelotas. Anais... Pelotas: Embrapa Clima Temperado, 2004. p.271-282. (Documentos, 124)

LIU, R.H. Health benefits of fruits: implications for disease prevention and health promotion. In: CONGRESSO BRASILEIRO DE FRUTICULTURA, 19., 2006, Cabo Frio. Palestras e resumos... Rio de Janeiro: SBF/UENF/UFRuralRJ, 2006. p.36-44.

MARO, L.A.C. ; SANTOS, L.O. ; MARTINS, R.N. ; FERNANDES, M.B. ; DIAS, M.S.C. ; CANUTO, R.S. ; SILVA, J.J.C. Teor de antocianina e flavonóis em morangos cultivados na região norte de Minas Gerais. In: CONGRESSO BRASILEIRO DE FRUTICULTURA, 18., 2004, Florianópolis. Anais... Florianópolis: SBF/EPAGRI/UFSC, 2004. CD ROM

NIENOW, A.A. Comportamento morfológico, fenológico e produtivo de cultivares de pessegueiro (Prunus persica $\mathbf{L}$. Batsch), submetidos à épocas de poda de renovação após a colheita na região de Jaboticabal, SP. 1997. 170 f. Tese (Doutorado em Agronomia/Produção Vegetal) - Faculdade de Ciências Agrárias e Veterinárias, Universidade Estadual Paulista, Jaboticabal, 1997.

OLIVEIRA, R.P. de; SCIVITTARO, W.B. Desempenho produtivo de mudas nacionais e importadas de morangueiro. Revista Brasileira de Fruticultura, Jaboticabal, v.28, n.3, p.520-522, 2006.

PAGOT, E.; HOFFMANN, A produção de pequenas frutas no Brasil. In: SEMINÁRIO BRASILEIRO SOBRE PEQUENAS FRUTAS, 1., 2003, Vacaria. Anais... Bento Gonçalves: Embrapa Uva e Vinho, 2003. p.9-18. (Documentos, 37).

PALLAMIN, M.L.; SAMPAIO, A.C.; FUMIS, T.F.; OLIVEIRA, O.M. Avaliação da produtividade de nove cultivares de morango na região de Bauru-SP. Horticultura Brasileira, Brasília, v.21, n.2, 2003. Suplemento. CD-ROM.

SANTOS, A.M. dos. Melhoramento genético do morangueiro. Informe Agropecuário, Belo Horizonte, v.27, n.198, p.24-29, 1999. 
SCHWENGBER, J.E.; PEIL, R.M.N; MARTINS, S; ASSIS DE F.N. Comportamento de duas cultivares de morangueiro em estufa plástica em Pelotas-RS. Horticultura Brasileira, Brasília, v.14, n.2,p.143-147, 1996.

SIMÕES, C.M.O.; SCHENKEL, E.P.; GOSMANN, G.; MELLO, J.C.P.; MENTZ, L. ; PETROVICK, P.R. Farmacognosia: da planta ao medicamento. 5.ed. Florianópolis/Porto Alegre: Editora UFSC/ UFRGS, 2003.378p.

SOUZA, L.T.; MARO, L.A.C.; LANZA, F.E.; DIAS, M.S.C.; SANTOS,L.O.; FERNANDES, M.B. Teor de antocianina e flavonóis em morangos cultivados sem a utilização de agrotóxicos no município de Mocambinho - MG. Produção do ano de 2004. In: CONGRESSO BRASILEIRO DE FRUTICULTURA, 19., 2006, Cabo Frio. Palestras e resumos... Rio de Janeiro: SBF/UENF/UFRuralRJ, 2006.
VERDIAL, M.F. Frigoconservação e vernalização de mudas de morangueiro (Fragaria $\mathrm{X}$ ananassa Duch.) produzidas em sistemas de vasos suspensos. 2004. $71 \mathrm{f}$. Tese (Doutorado em Agronomia/Fitotecnia) - Escola Superior de Agricultura "Luiz de Queiroz”, Universidade de São Paulo, Piracicaba, 2004. 